\title{
Building Performance Evaluation - A design approach for refurbishment of a small traditional building in Scotland
}

\author{
J. A. Foster ${ }^{1}$, S. A. Foster ${ }^{2}$, T. R.Sharpe ${ }^{1}$ and A. Poston ${ }^{1}$.
}

\author{
${ }^{1}$ Mackintosh Environmental Architecture Research Unit, The Glasgow School of Art, (GSA), Glasgow, Scotland. \\ j.foster@gsa.ac.uk; t.sharpe@gsa.ac.uk \\ ${ }^{2}$ Sam Foster Architects, (SFA), Dunfermline, Scotland. sam@samfosterarchitects.co.uk
}

\begin{abstract}
The drive for carbon dioxide $\left(\mathrm{CO}_{2}\right)$ emission reductions has, in recent years, seen thermal improvements being made to the fabric of historic buildings. This paper discusses, through a case study, the use of Building Performance Evaluation (BPE) to inform refurbishment design of the community owned Land Sea and Islands Centre, located in Arisaig, Scottish Highlands. This is a $19^{\text {th }}$ century stone building with high heat losses, inefficient heating and lighting systems, resulting in occupant discomfort and high running costs. Funding was awarded in 2014 to improve its energy performance. Pre-refurbishment BPE results identified areas of significant heat loss, low internal surface temperatures, discrepancies between predicted and measured U-values, thermal bridges and excessive air infiltration. Refurbishment was completed in June 2015 and post-refurbishment BPE utilised to quantify improvements in building fabric, energy consumption and comfort levels, advocating pre-refurbishment BPE as a beneficial tool for informing traditional building refurbishment.
\end{abstract}

Keywords - Refurbishment; Building Performance Evaluation; Energy; Air Permeability; Indoor Air Quality

\section{INTRODUCTION}

Understanding our historic building stock is essential to allow sympathetic refurbishments to be made to support the Scottish $42 \%$ emission reduction by 2020 and $80 \%$ by 2050 [1]-[2]. The drive for these reductions has shifted to include the refurbishment of existing and historic building stock with upgrades to building fabric and heating systems becoming common [3]. In most cases there is a greater challenge involved in adapting historic buildings for energy efficiency [4] as their retrofit requires a different pallet of materials and construction techniques than most new builds [5]. If not adopted, damage can occur to the original building fabric, with performance and character being compromised [6]. If undertaken correctly retrofit works can upskill the workforce [7], which is particularly important for energy efficiency measures applied to non-listed buildings that contribute to cultural heritage.

Building Performance Evaluation (BPE) on historic buildings is not common practice, but when $\mathrm{BPE}$ is undertaken it is more routinely conducted post-construction to review performance of new buildings. The resultant findings are typically disseminated to the client group and designers to facilitate improvements in their design practices. This paper focuses on a case study of an existing $19^{\text {th }}$ Century building where BPE was used to inform its refurbishment. The Land Sea and Islands Centre 
(LSIC) (Figure 1), is a $79 \mathrm{~m}^{2}$ former blacksmiths located in the centre of Arisaig, a rural coastal village in the north west of Scotland. In 1999 the building underwent major renovation including replacement windows, insulation to ceilings and selected external walls, the construction of three extensions and application of cement render to the external walls. Subsequently the building was used to house artefacts and documents promoting the local heritage and operated as a visitor centre. In 2012 Arisaig Community Trust (ACT) took ownership of LSIC, however, the LSIC remained closed throughout the winter as ACT experienced difficulty in heating the building above $16^{\circ} \mathrm{C}$ and the lighting was expensive to run. In 2014 ACT were awarded a Climate Challenge Fund (CCF) grant for the energy efficient refurbishment, with projected energy improvements of $75 \%$.

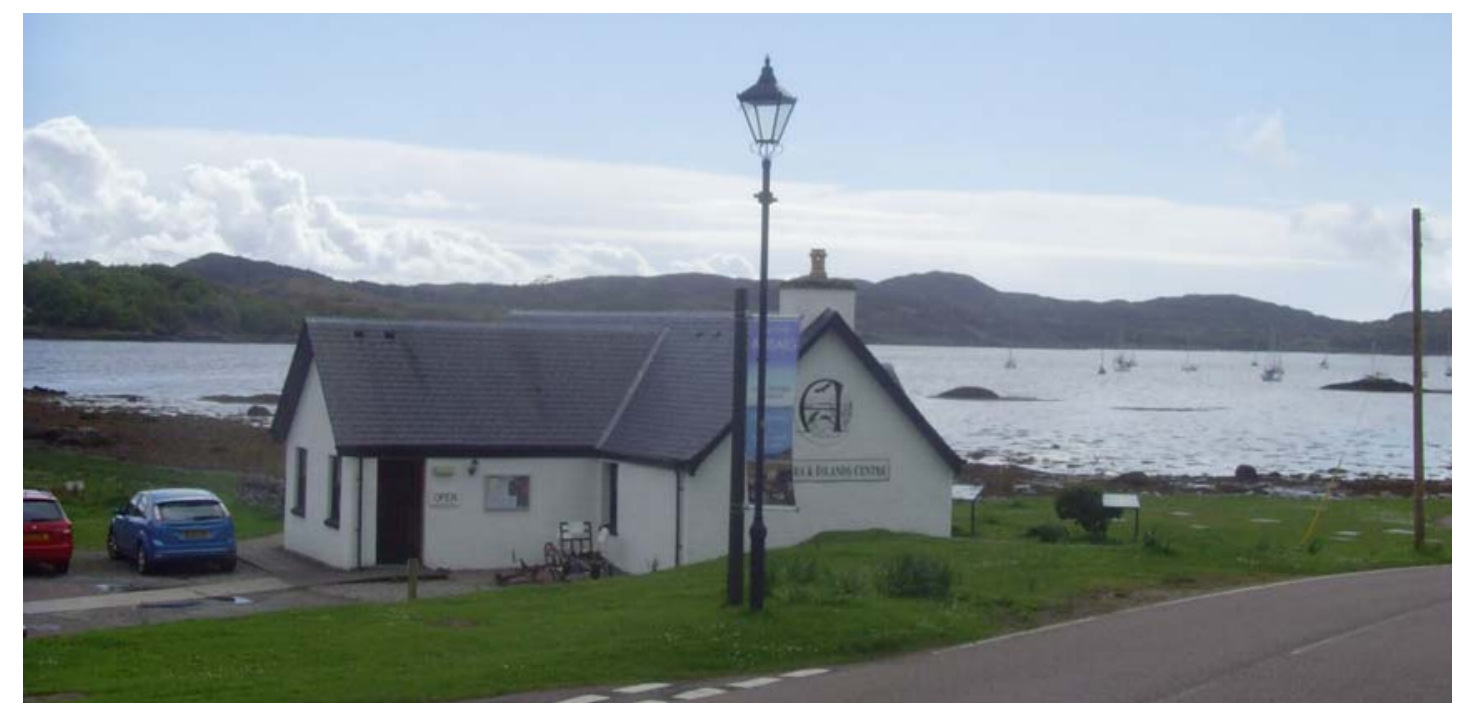

Figure 1. View of LSIC building, north facing entrance and reception and north gable wall of exhibition area.

Sam Foster Architects (SFA) were appointed and developed design proposals using materials compatible with the existing historic building. These measures were applied to the 'Exhibition Room' and 'Room with a View' (RWV); they have not been applied to the shop area, which is planned to be replaced with a larger, energy efficient extension. To accurately identify areas of high heat loss and assess the internal thermal environment SFA approached Mackintosh Environmental Architectural Research Unit (MEARU) to assist, jointly applying for grant funding from the Scottish Funding Council (SFC) for pre-refurbishment (PR1) BPE. The outputs provided a 'PR1' benchmark against which a subsequent 'post-refurbishment' (PR2) BPE could be compared. The six-month refurbishment commenced in January 2015 and further funding was sought through Zero Waste Scotland (ZWS) to conduct PR2 BPE.

\section{METHODOLOGY}

PR1 BPE was conducted throughout December 2014 and the study was repeated in December 2015, post-refurbishment. To assess the thermal performance of the building quantitative and 
qualitative testing was undertaken. The qualitative assessment comprised a semi-structured questionnaire completed by those employed or volunteering at LSIC and included comfort polling and assessment of the user understanding for building operation. The quantitative element consisted of building fabric testing, environmental assessment and energy consumption monitoring. The building fabric testing included air permeability testing with thermography and in-situ U-value measurements. Air permeability testing was undertaken in accordance with the Air Tightness Testing and Measurement Association (ATTMA) guidelines [8]. Thermography, conducted during the Air Permeability Testing, was used as a tool to detect air movement patterns beneath the finished surfaces. U-value measurements were taken on four building elements: a ceiling element, insulated external wall (two separate locations), and an uninsulated external stone wall with rubble core. The methodology for measurement and subsequent analysis followed the procedures set out in ISO9869:1994 [9]. Due to the orientation of the building it was not possible for all measurements to be on north facing elements, therefore apparatus was installed to east facing ceilings, two insulated walls and one north facing stone gable.

Internal environmental monitoring was undertaken in three rooms using data loggers recording internal temperature $\left({ }^{\circ} \mathrm{C}\right)$ and relative humidity $(\mathrm{RH})$, and separate but adjacent data loggers for carbon dioxide concentration $\left(\mathrm{CO}_{2}\right)$ monitoring. External ${ }^{\circ} \mathrm{C}$ and $\mathrm{RH}$ measurements were recorded at the gable wall located on the north and north-east of the building. These instruments were set to simultaneously log at five minute intervals through the assessment period.

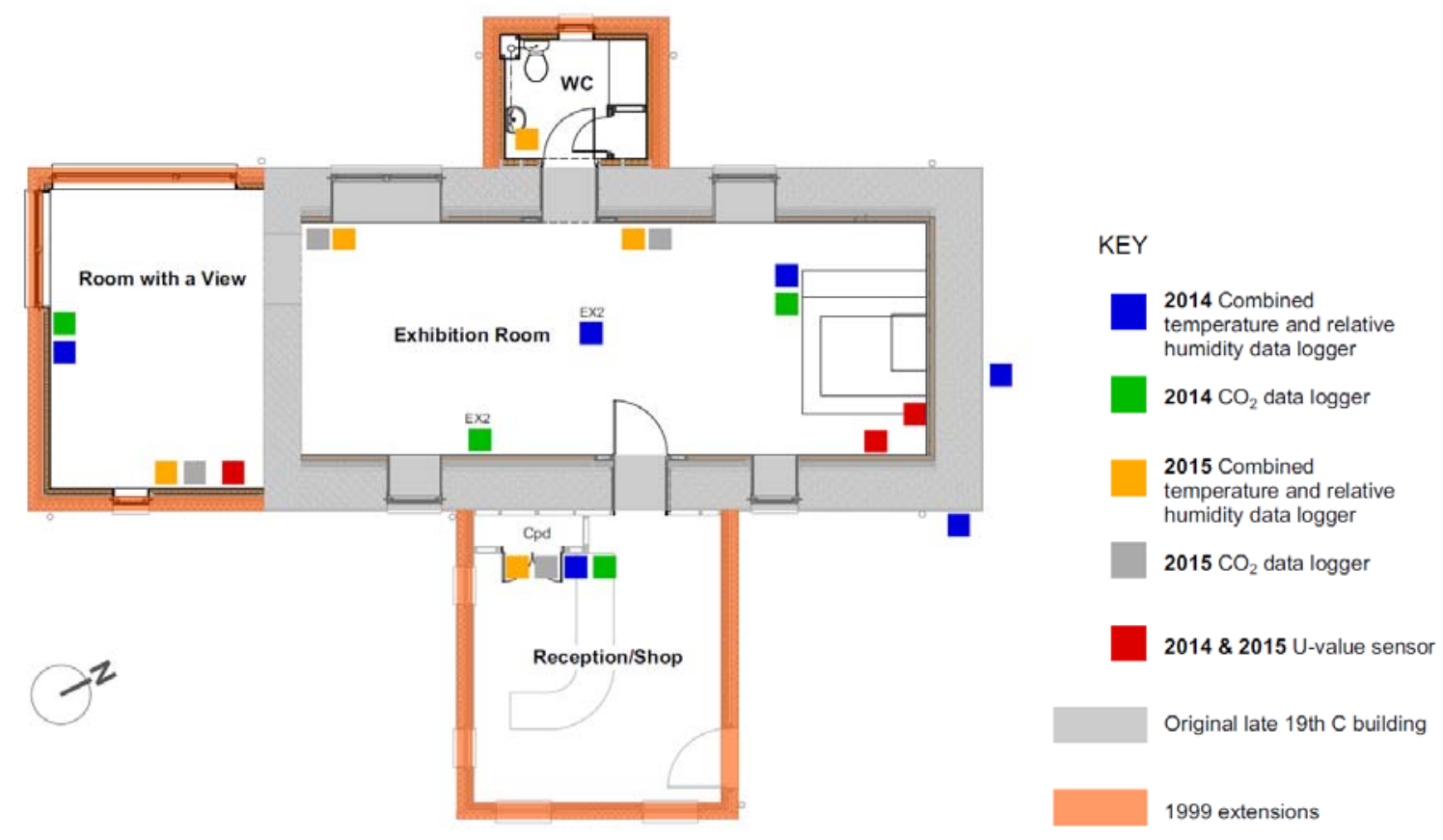

Figure 2. Plan view of LSIC building, indicating the historic core, 1999 extensions and location of monitoring apparatus for pre and post-refurbishment BPE. 
During the PR1 study LSIC maintained a manual log of meter readings for the two electricity meters serving space heating and mains consumption. The metering arrangement was altered during refurbishment works and PR2 monitoring used ACT's energy monitor for space heating consumption. This monitor was display only and did not record, so manual recordings were taken from this by the LSIC staff twice per day. A meter was used on the lighting circuit, recording directly to a web application and the building's mains consumption was manually recorded.

\section{RESULTS}

The PR1 air permeability testing revealed the building experienced excessive infiltration (Table 1). While the building was held under negative pressure air pathways were traced using smoke pencil and thermography tests. This confirmed locations where infiltration was most severe, most notably in areas where the three 1999 extensions joined the existing building, at the ceiling, joist ends, mains electricity cable point of entry and around the soil vent pipe located behind the WC. In contrast, the PR2 testing indicated an $85 \%$ reduction in air infiltration rates. However, infiltration rates remained significant in the shop area, which was not subject to the same level of refurbishment as the rest of the building.

Table 1. Air Permeability measurements pre and post refurbishment

\begin{tabular}{cccc}
\hline \multirow{2}{*}{ Test } & \multicolumn{3}{c}{ Air Permeability Measurements $\left(\mathbf{m}^{\mathbf{3}} \mathbf{h} . \mathbf{m}^{\mathbf{2}}\right.$ @ 50Pa) } \\
& Negative & Positive & Mean \\
\hline Pre-Refurbishment & 16.76 & 19.32 & 18.04 \\
\hline Post-Refurbishment & 2.61 & 2.79 & 2.70 \\
\hline
\end{tabular}

The thermography, performed together with the airtightness testing, visually identified these infiltration pathways. In the pre-refurbishment state areas of missing insulation and air passages behind plasterboard and timber linings were identified. Figure 3 and Figure 4 illustrate the contrast between the before and after refurbishment thermography of the north west area of the exhibition room. PR1 thermograms were taken during December 2014 and PR2 thermography in February 2016. These were undertaken to indicate air movement patterns present behind the finished surfaces.

The results in Table 2 illustrate that the pre-refurbishment measurements did not meet the building regulation requirements at the time of installation. Manual steady-state calculations, based on the 1999 'as built' drawings, using thermal properties of materials obtained from best practice guidance, indicate inaccurate assumptions were available for the U-values during the design process. In contrast the post-refurbishment measurements confirm a $63 \%, 45 \%, 16 \%$ and $57 \%$ improvement in $\mathrm{U}$-Value in building elements A, B, C and D respectively. 


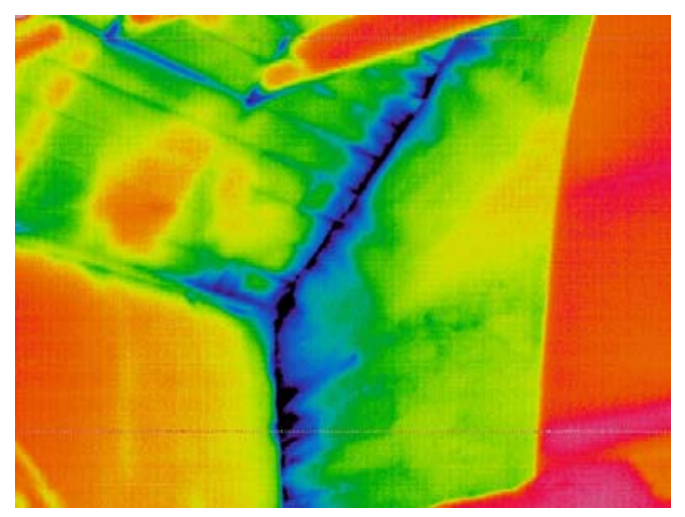

Figure 3. Thermogram of where the uninsulated north gable joins with insulated west wall and ceiling, indicating significant air leakage at joist ends, cool spots behind timber ceiling and air ingress at the corner.

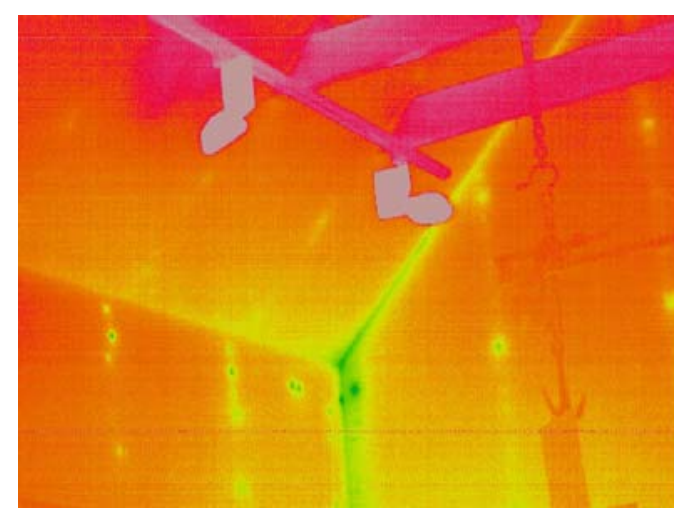

Figure 4. Thermogram of where the newly insulated and lined north gable joins with re-insulated west wall and ceiling, indicating slightly cooler area at the corner and no cooler area at joist ends.

Table 2. Comparison of predicted $U$-Value with pre and post refurbishment measured $U$-Values $W / \mathrm{m}^{2} \mathrm{~K}$

\begin{tabular}{cllccccc}
\hline Surface & Room & $\begin{array}{c}\text { Building } \\
\text { Element }\end{array}$ & Orientation & $\begin{array}{c}1999 \\
\text { Elemental } \\
\text { U-Values }\end{array}$ & $\begin{array}{c}\text { SFA } \\
\text { Manual U- } \\
\text { Value }\end{array}$ & $\begin{array}{c}\text { In-Situ U- } \\
\text { Value Pre } \\
\text { Refurbishment }\end{array}$ & $\begin{array}{c}\text { In-Situ U- } \\
\text { Value Post } \\
\text { Refurbishment }\end{array}$ \\
\hline A & RWV & Ceiling & East & 0.20 & 0.43 & 0.72 & 0.26 \\
\hline B & RWV & Lined wall & East & 0.30 & 0.49 & 0.40 & 0.22 \\
\hline C & Exhibition & Lined wall & East & 0.30 & 0.49 & 0.25 & 0.21 \\
\hline D & Exhibition & Stone wall & North & n/a & 1.64 & 0.93 & 0.40 \\
\hline
\end{tabular}

The temperature comparison in Figure 5 indicates that both of the minimum and mean internal temperatures have improved from $8^{\circ} \mathrm{C}$ and $13^{\circ} \mathrm{C}$ respectively by $4^{\circ} \mathrm{C}$ compared to the PR2 monitoring. The PR2 temperatures provide a more comfortable internal environment with less of a temperature swing. The indoor maximum RH for December 2014 and 2015, shown in Figure 6, indicates a 10\% reduction in the two rooms that underwent major refurbishment. Although the reception $\mathrm{RH}$ has reduced, the maximum $\mathrm{RH}$ remains close to $70 \% \mathrm{RH}$ which can negatively affect the building fabric and artefacts within this area.

The electrical consumption relied primarily on manual data collection, during the second tranche of monitoring a power cut reset the data collection device, negating daily comparisons. Using meter readings made at the start and end of each monitoring period a $57 \%$ reduction in energy consumption was achieved compared to the December of the previous year. 


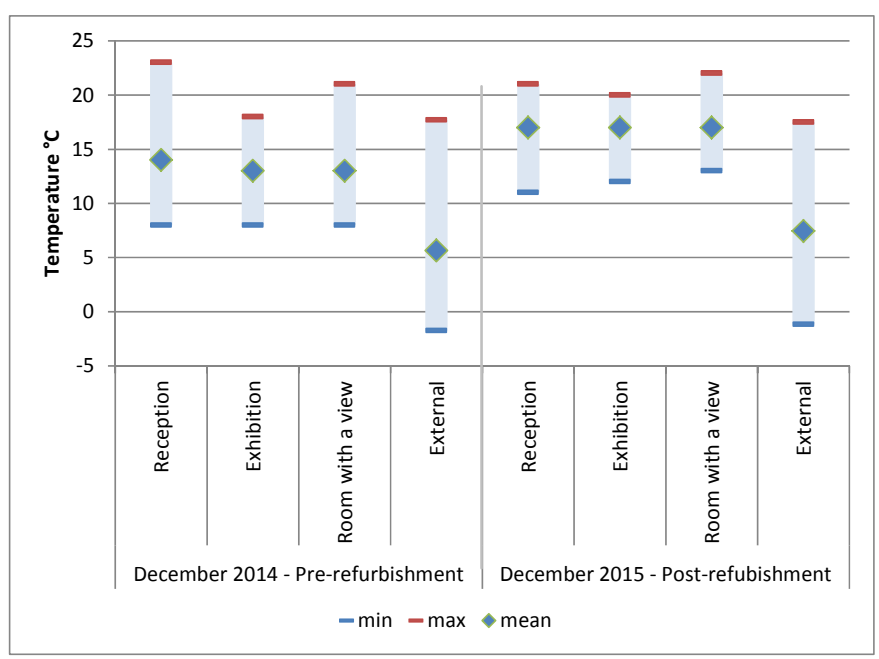

Figure 5. Minimum, maximum and mean temperature comparison, 2014 and 2015 monitoring.

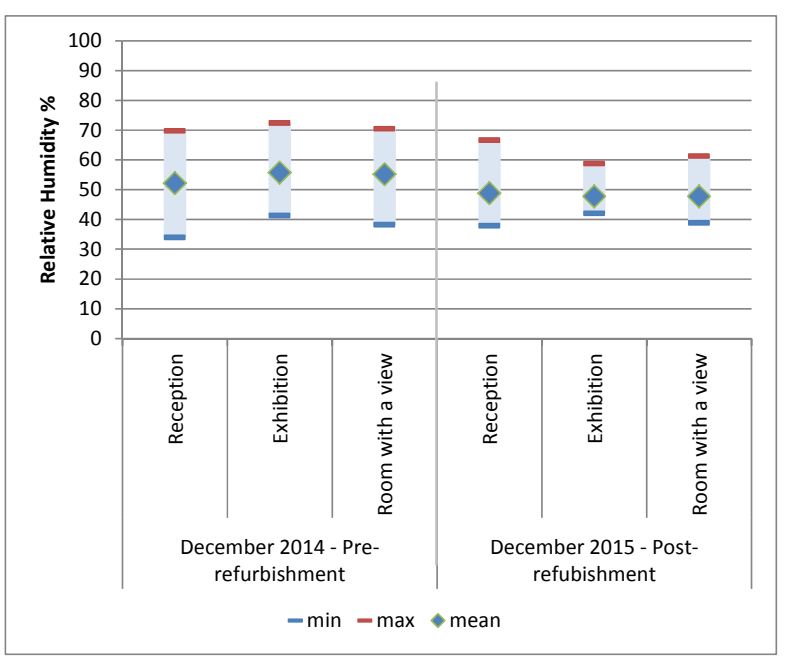

Figure 6. Minimum, maximum and mean relative humidity comparison, 2014 and 2015 monitoring.

\section{DISCUSSION}

There are a number of justifications for refurbishing existing listed and unlisted traditional buildings, including sustainability and the conservation of cultural heritage. Many of these buildings, particularly in smaller settlements with fewer buildings, are cultural landmarks with which residents and visitors have some form of attachment. Increasing support from EU, central and local government is resulting in local community groups undertaking ownership and maintenance of small traditional buildings in their towns and villages. With the Land Reform (Scotland) Act 2003 [10] and the Community Empowerment (Scotland) Act 2015 [11] this trend is likely to continue and the work carried out by communities will become more common as community groups seek to minimise their running costs. In Scotland 20\% of the building stock was constructed pre-1919 [6][12], therefore a large number of people and communities are affected by the need to refurbish appropriately. Case studies of sensitive and appropriate refurbishment of small traditional buildings have the potential to provide clear, relevant information to homeowners who are considering improving the energy efficiency of their homes.

The improvements to thermal performance and comfort post-refurbishment highlight the positive impact BPE has made to the upgrading of the LSIC building. While the architect had planned for improved airtightness and insulation measures to be applied to the building, using natural vapour open building materials, the initial BPE results vindicated the architects design intent and highlighted the areas where particular attention was required. For example, the in-situ U-value testing indicated the heat transmission through the stone walls was less than expected allowing proposed insulation thickness to be reduced. This provided a cost saving which allowed an offset against additional insulation measures to the buildings ceiling that had exhibited poorer thermal characteristics than anticipated through using steady state manual calculations. As the measurement of U-values may not 
be practical in every situation, the inconsistent results provided by the steady state calculations indicate thermal property assumptions for building materials in best practice guidance documents is perhaps outdated and requires updating, to allow for more accurate predictions of U-values in existing buildings.

The use of vapour open building materials and finishes such as lime plaster, wood fibre and sheeps wool insulation and natural paint finishes could, according to manufacturer's literature, benefit the hygrothermal performance of the building. The initial results indicate improved hygrothermal performance in the exhibition room and room with a view where hygroscopic building materials were applied. However the aim of the monitoring was not to undertake assessment of hygrothermal performance and further research would be required to evaluate this. It would be advantageous to monitor hygrothermal conditions before and after the planned removal of the external cement render during the next phase of refurbishment.

The predicted energy reductions originally were set to achieve a $75 \%$ reduction in $\mathrm{CO}_{2}$ emissions from the building have not been reached, however, the 57\% energy reduction is a significant improvement, which will improve as the users become accustomed to optimising building use. The overarching result is that ACT are now able to heat LSIC to a comfortable temperature, permitting regular opening hours during the winter months and increased demand for the building's use during evenings for local community events. The extended use and opening hours may have impacted on the additional energy consumption but the refurbishment has delivered positivity in the village. Moreover the control over the internal environment has provided a reduced and more stable RH protecting the condition of the artefacts on display within the building and safeguarding the local heritage. The sympathetic refurbishment and comfortable environment has prompted the local community to refurbish homes of similar construction to improve energy efficiency within the village, some using airtightness permeability testing prior to refurbishment to indicate where works need to be undertaken.

\section{CONCLUSION}

This paper presents a case study of a historic building that used BPE as part of the design process. The PR1 indicated that the earlier retrofit in 1999 did not meet the building regulations at the time, which, combined with the excessive infiltration, meant that the building was underheated (even with the heating at maximum output) and unused during the winter months as the occupants found it too uncomfortable. Although the refurbishment included natural building materials compatible with historic buildings, the CCF refurbishment grant funding did not cover the removal of cement render applied in 1999, which impacts on historic building thermal and hygroscopic performance [6]. LSIC are planning to remove the cement render in the future.

Improvements to the building have not only improved the energy efficiency but created a more comfortable and useable space that has greatly impacted on the users and wider community. It is also worth noting that although the original CCF grant required $75 \%$ carbon reductions, no measures were 
built into the framework to check whether these savings were achieved. It is recommended that further research be undertaken into building performance gap closure in relation to grant funding for energy efficient refurbishments, as well of the impact of these on the building fabric as a whole.

The BPE project provided tangible results for the sympathetic refurbishment of a historic building, which can be replicated in similar traditional properties in the area. However, owners (individual and community groups) of non-listed traditional buildings require better access to support and information that can help with improving energy efficiency of their homes. More research is required into undertaking pre- and post-refurbishment BPE and the accessibility of these tools and information for the general public.

\section{ACKNOWLEDGEMENTS}

Scottish Funding Council for funding the pre-refurbishment BPE and to Zero Waste Scotland for funding post-refurbishment BPE. Without the funding input from both organisations the study would not have been possible. The Land Sea and Islands Centre staff and volunteers played an instrumental role in the BPE and having endured monitoring equipment in the building during the busy Christmas holiday period for two consecutive years.

\section{REFERENCES}

[1] The Scottish Government, Low Carbon Scotland: Meeting the Emissions Reduction Targets 2010-2022: RPP1. 2010.

[2] The Scottish Government, Low Carbon Scotland: Meeting our emissions reduction targets 2013-2027, the draft second report on proposals and policies. 2013.

[3] Scottish Government, Conserve and Save: The Energy Efficiency Action Plan for Scotland, no. October. 2010.

[4] J. Swinney, "National planning framework for Scotland: 2," 2009.

[5] G. Franco, A. Magrini, M. Cartesegna, and M. Guerrini, "Towards a systematic approach for energy refurbishment of historical buildings. the case study of Albergo dei Poveri in Genoa, Italy," Energy Build., vol. 95, pp. 153-159, 2015.

[6] Historic Scotland, "Short Guide: Fabric improvements for energy efficiency in traditional buildings," pp. 1-37, 2012.

[7] Scottish Government, A Low Carbon Economic Strategy for Scotland: Scotland a Low Carbon Society. 2010.

[8] Air Tightness Testing and Measurement Association (ATTMA) Website: https://attma.org/air-tightness-testingrequirements/ [Accessed $18^{\text {th }}$ Feb 2016].

[9] ISO9869:1994 Thermal insulation- Building elements - In-situ measurement of thermal resistance and thermal transmittance. http://www.iso.org/iso/home/store/catalogue ics/catalogue detail ics.htm?csnumber=17746 [Accessed $18^{\text {th }}$ Feb 2016].

[10] The Scottish Executive and Open Access, “Land Reform ( Scotland ) Act 2003,” vol. 2003, no. asp 2, 2003.

[11] The Scottish Government "Community Empowerment ( Scotland ) Act 2015," 2015.

[12] G. Mueller, C. Leadbetter, S. Palombi, and J. Robertson, "Scottish House Condition Survey : 2014 Key Findings,” p. $126,2015$. 